\section{P45 OUTCOMES FOLLOWING PULMONARY REHABILITATION FOR PATIENTS WITH RESTRICTIVE LUNG DISEASES WITH OR WITHOUT OXYGEN THERAPY}

doi:10.1136/thx.2010.150961.45

V L Warrington, J Scullion, L Sewell, J Williams, S Singh. University Hospitals of Leicester NHS Trust, Leicester, UK

Introduction To review the outcome of pulmonary rehabilitation (PR) for patients with restrictive lung diseases who do or not have oxygen therapy.

Methods 10 years of PR data were searched for patients with Interstitial Lung Disease (ILD), Pulmonary Fibrosis (PF) or Cryptogenic Fibrosing Alveolitis (CFA) who had completed PR. PR classes were twice weekly for 7 weeks which consisted of training based on a walking programme, static bike and strength exercises. Exercise capacity measured by Incremental Shuttle Walk Test (ISWT) and Endurance Shuttle Walk Test (ESWT), health status measured by Hospital Anxiety and Depression Scale (HADS) and Chronic Respiratory Questionnaire - self-reported (CRQ) results were analysed.

Results 25/81 patients who had completed PR were oxygen users: 16 male, mean(SD) age 69.8 (7.7) years; FEV 1 1.95(0.63) 1; FVC 2.52 (0.8) I; FEV 1 /FVC 81.83 (8.43)\%; BMI 28.6 (5.97). 10 had ambulatory, 5 had long term and 10 used short-burst oxygen therapy with a median flow rate of $41 / \mathrm{min}$. Patients without oxygen were 72.3 (9.5) years with a FEV 1 1.84(0.61) 1; FVC 2.41 (0.68) 1; FEV 1 /FVC 78.58 (7.3)\%; BMI 27.65(5.05); 33 male. Independent T-Tests revealed the only significant baseline difference between the groups was resting oxygen saturation $\left(\mathrm{SaO}_{2}\right)$ with oxygen users having a mean $\mathrm{SaO}_{2}$ of $90.5 \%$ compared to non-oxygen users' $\mathrm{SaO}_{2}$ being $94.8 \%$ $(\mathrm{p}=0.001)$. Paired T-Tests were performed between baseline and discharge scores for both groups (Abstract P45 Table 1). Those not using oxygen improved their mean change in ISWT $(p=0.026)$ and ESWT ( $p=0.039$ ) scores between baseline and discharge significantly more than those using oxygen. Oxygen users had significantly $(\mathrm{p}<0.001)$ lower $\mathrm{SaO}_{2}$ levels after performing ISWT $(78 \%$ compared to $89 \%$ ) and ESWT (78\% compared to $87 \%$ ) than those not using oxygen.

Abstract P45 Table 1 Baseline and mean change in PR outcome measures for patients using or not using oxygen

\begin{tabular}{|c|c|c|c|c|c|c|}
\hline \multirow{2}{*}{ Measure } & \multicolumn{3}{|c|}{ Oxygen } & \multicolumn{3}{|c|}{ Not on oxygen } \\
\hline & $n=$ & Baseline & Mean (SD) Change & $\mathbf{n}=$ & Baseline & Mean (SD) Change \\
\hline ISWT (m) & 25 & 185.6 & $14.4(60.7)$ & 55 & 195.6 & $46.5^{* *}(58.0)$ \\
\hline ESWT (s) & 21 & 140 & $125^{* *}(164)$ & 40 & 189 & $362^{* *}(378)$ \\
\hline MRC & 19 & 3.55 & $-0.25(0.91)$ & 35 & 3.49 & $-0.46^{* *}(0.89)$ \\
\hline CRQ-Dyspnoea & 17 & 2.12 & $0.50 *(0.94)$ & 35 & 2.69 & $0.70^{* *}(0.97)$ \\
\hline CRQ-Fatigue & 17 & 3.31 & $0.59(1.45)$ & 37 & 3.30 & $0.59 * *(1.25)$ \\
\hline CRO-Emotion & 17 & 4.45 & $0.33(1.25)$ & 37 & 4.40 & $0.56 * *(1.01)$ \\
\hline CRO-Mastery & 17 & 4.49 & $0.27(1.15)$ & 37 & 4.20 & $0.59 * *(0.92)$ \\
\hline HADS-Anxiety & 17 & 6.5 & $-1.7(3.5)$ & 29 & 7.9 & $-1.3(3.6)$ \\
\hline HADS-Depression & 15 & 6.3 & $-1.5^{*}(2.5)$ & 29 & 6.2 & $-1.3^{*}(3.1)$ \\
\hline
\end{tabular}

Conclusion PR produces positive outcomes for patients with ILD, CFA or PF. Improvements in exercise capacity and health status for non-oxygen users were statistically and clinically significant, more so than for oxygen users. Those using oxygen de-saturated more than those not using oxygen after performing the SWTs. As both groups of patients benefited, PR should be offered to all patients with restrictive lung diseases irrespective of oxygen use, although the typical PR programme may need some adjustment for oxygen users to gain more benefit.

\section{P46 EFFECTS OF PHYSICAL ACTIVITY TOP UP 'PAT ON THE BACK' PROGRAMME ON EXERCISE CAPACITY AND HEALTHCARE UTILISATION FOR PEOPLE WITH CHRONIC OBSTRUCTIVE PULMONARY DISEASE (COPD)}

doi:10.1136/thx.2010.150961.46

${ }^{1} \mathrm{G}$ Arbane, ${ }^{2} \mathrm{~A}$ Douiri, ${ }^{2} \mathrm{~L}$ Enright, ${ }^{2} \mathrm{~L}$ Haggis, ${ }^{3} \mathrm{~T}$ Poulter, ${ }^{2} \mathrm{R}$ Garrod. ${ }^{1} \mathrm{~S} t$ George's University of London, London, UK; ${ }^{2}$ King's College, London, UK; ${ }^{3}$ Wandsworth Primary Care Trust, London, UK

Introduction Pulmonary rehabilitation (PR) is a proven effective treatment, however benefits tend to decline between 6 and 12 months post rehabilitation. Randomised controlled trials of maintenance programmes show little effect of supervised maintenance after PR However, a short intense bout of physical training, provided post rehabilitation may be sufficient to restore exercise tolerance. This study tests the hypothesis that a Physical Activity Top up programme (PAT on the back) will result in improvements in exercise tolerance as compared with no top up.

Methods 31 patients with stable COPD, who had undertaken Pulmonary rehabilitation (PR) at least 6 months previously were randomised to 4 weeks of PAT exercise once weekly or usual care. Incremental Shuttle Walk Test (ISWT) data were collected pre PAT (T1), post PAT (T2) and 3 months end of PAT programme (T3). QoL (SGRQ) and breathlessness (LCADL) were measured at the same time points. Generalised estimating equation (GEE) regression models and univariate analysis of variance were used to analyse data where subjects performed all assessments and ISWT results from end PR was used as covariate, with ISWT as dependant variable.

Results 23 subjects completed all assessments. The intervention group increases $0.9 \mathrm{~m}$ for every $1 \mathrm{~m}$ increase achieved at $\mathrm{T} 1$, $\mathrm{p}=0.027$. The intervention group shows an overall improvement of $47.3 \mathrm{~m}$, with an average increase of $17.26 \mathrm{~m}$ per time point. A significant time effect $(p=0.02)$ mean difference (SD) T1-T3 in control group showed the intervention group were $79.6 \mathrm{~m}$ improved with CI 15 to 143.8. There was no group or time effect for QoL or LCADL (Abstract P46 Figure 1).

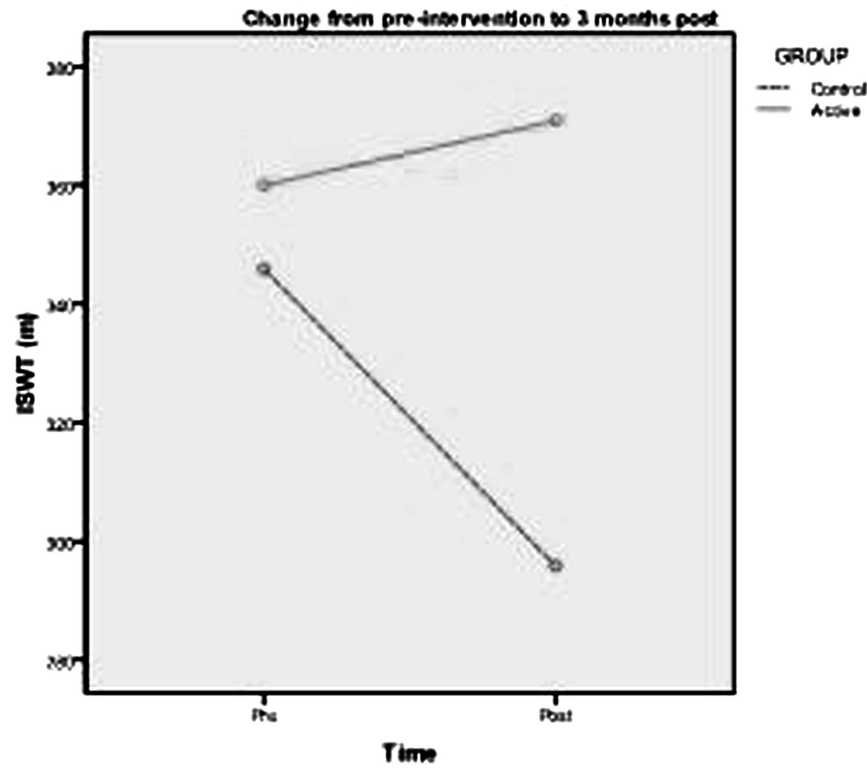

Abstract P46 Figure 1

Conclusion A brief 4 week intervention 'PAT on the back' did little to change QoL or breathlessness but was effective in maintaining exercise tolerance over a 3 month period compared to usual care in which walking distance significantly deteriorated. 